\title{
Utilization, Cost Trends, and Member Cost-Share for Self-Injectable Multiple Sclerosis Drugs-Pharmacy and Medical Benefit Spending From 2004 Through 2007
}

\author{
April M. Kunze, PharmD; Brent W. Gunderson, PharmD; Patrick P. Gleason, PharmD, FCCP, BCPS;
} Alan H. Heaton, PharmD; and Steven V. Johnson, PharmD, BCPS

\begin{abstract}
BACKGROUND: In 1993, interferon beta-1b became the first of 4 selfinjectable multiple sclerosis (MS) drugs to be approved by the U.S. Food and Drug Administration. Initially covered as a medical expense, selfinjectable MS drugs are increasingly considered specialty pharmaceuticals and are often covered under the pharmacy benefit. Self-injectable MS drugs are expensive, costing approximately $\$ 2,000$ per month per patient in 2007.

OBJECTIVES: To (1) determine the trends for price and utilization of selfinjectable MS drugs, (2) meld medical and pharmacy claims data to capture total health care spending on self-injectable MS drugs, and (3) calculate the out-of-pocket cost-share for members with pharmacy benefits.
\end{abstract}

METHODS: A pharmacy benefits manager with integrated medical claims for approximately 1.8 million commercial members, about $20 \%$ of its total of 9 million commercial members, analyzed self-injectable MS pharmacy claims for a 45-month period beginning in January 2004 and ending in September 2007 and integrated medical and pharmacy claims for a 42-month period beginning in January 2004 and ending in June 2007. The 9 million members are beneficiaries of 10 Blue Cross Blue Shield (BCBS) health plans distributed throughout the United States, and the subset of 1.8 million members are enrolled in 1 BCBS health plan in the Northern Plains states. Self-injectable MS drugs were identified using Generic Product Identifier (GPI) codes for the National Drug Code (NDC) numbers on pharmacy claims. Mail order pharmacy claims with up to a 90-day supply were counted as 3 claims, and community pharmacy claims dispensed with up to a 34-day supply were counted as 1 claim. Self-injectable MS drugs were identified from medical claims using Healthcare Common Procedure Coding System (HCPCS) codes: J1595 for glatiramer, J1830 for subcutaneous interferon beta-1b, Q3026 for subcutaneous interferon beta-1a, and Q3025 and J1825 for intramuscular interferon beta-1a.

RESULTS: For the approximately 9 million members with data from pharmacy claims only, these 4 self-injectable MS drugs accounted for approximately $1.8 \%$ of total pharmacy benefit spending in $2004,1.9 \%$ in $2005,2.3 \%$ in 2006 , and $2.4 \%$ in 2007 . The mean average wholesale price (AWP) per member per month (PMPM) increased by $56.8 \%$, from $\$ 1.11$ PMPM in the first quarter of 2004 to $\$ 1.74$ PMPM in the third quarter of 2007. Utilization was flat at about $82-83$ claims per 100,000 members per month during the 45 -month measurement period. The average annual price increase per unit ranged from $8.9 \%$ for interferon beta-1a to $13.3 \%$ per year for interferon beta-1b. Members paid a median out-of-pocket cost per pharmacy claim of \$15 in 2004, \$20 in 2005 and 2006, and \$25 in the first 9 months of 2007. For the 1.8 million members with both pharmacy and medical benefit claims, the medical benefit accounted for $2.5 \%$ of total spending on MS self-injectables in 2004, 2.0\% in 2005 and 2006, and $1.2 \%$ in 2007.
CONCLUSION: The percentage of all pharmacy expenditures that was attributable to self-injectable MS drugs increased from $1.8 \%$ in 2004 to $2.5 \%$ in 2007 . Nearly all of the increase in spending on self-injectable MS drugs over the nearly 4-year period was attributable to drug price increases because PMPM utilization was essentially unchanged. The median member cost-share was approximately $1 \%$ of the total cost of self-injectable MS drugs.

J Manag Care Pharm. 2007;13(9):799-806

Copyright@ 2007, Academy of Managed Care Pharmacy. All rights reserved.

\section{What is already known about this subject}

- Previous administrative claims research found an incidence of multiple sclerosis (MS) diagnosis code 340 (International Classification of Diseases, Ninth Revision, Clinical Modification, ICD-9-CM) of 140 per 100,000 patients in 2004 and average annual medical care costs of $\$ 12,879$ per MS patient, $64.8 \%$ of which was attributable to prescription drugs. ${ }^{10}$

- Total annual inflation-adjusted MS treatment costs increased by $35 \%$ over the 10 -year period, from $\$ 9,515$ per patient in 1995 to $\$ 12,879$ in $2004 .^{10}$

\section{What this study adds}

- Pharmacy claims accounted for $97.5 \%$ of total medical and pharmacy benefit spending on the 4 self-injectable MS drugs in $2004,98.0 \%$ in 2005 and 2006, and $98.8 \%$ in the first 9 months of 2007.

- The mean AWP per member per month (PMPM) for the 4 self-injectable drugs increased by 57\% from $\$ 1.11$ PMPM in the first quarter of 2004 to $\$ 1.74$ PMPM in the third quarter of 2007, or an average annual increase of approximately $12 \%$. Since utilization was essentially flat at $82-83$ claims per 100,000 members per month during the 45-month measurement period, price rather than utilization accounted for this $57 \%$ increase in PMPM cost.

- Members paid a median cost-share of approximately $1 \%$ of the total cost of self-injectable MS drugs over the period from 2004 through the first 9 months of 2007. 


\section{Utilization, Cost Trends, and Member Cost-Share for Self-Injectable Multiple Sclerosis Drugs- Pharmacy and Medical Benefit Spending From 2004 Through 2007}

$\mathrm{M}$ ultiple sclerosis (MS) is a progressive autoimmune disease that attacks the central nervous system, causing a range of symptoms that can progress to disability. MS affects approximately 400,000 Americans. ${ }^{1}$ Because of the subclinical disease activity early in the disease process, current expert opinion is that treatment of MS should be initiated early with a disease-modifying agent (DMA) for the best outcomes, including reducing relapses and slowing the progression of disability. ${ }^{2-4}$ Therapy is generally initiated with either interferon beta or glatiramer acetate (DMAs) and is continued indefinitely. ${ }^{3,5,6}$ There are no guidelines to recommend one self-injectable MS therapy over another.

Currently, 6 DMAs are approved by the U.S. Food and Drug Administration (FDA) for treating MS (Table 1). The 4 self-injectable drugs-intramuscular (IM) interferon beta-la (Avonex), subcutaneous (SC) interferon beta-la (Rebif), interferon beta-lb (Betaseron), and glatiramer acetate (Copaxone) - are the focus of this analysis. Natalizumab (Tysabri) and mitoxantrone (Novantrone) are infused intravenously, are typically administered in an outpatient setting, and account for less than $0.2 \%$ of DMA pharmacy claims. Of note, 2 of the FDA-approved medications are the same chemical entity (interferon beta-1a) produced by similar recombinant DNA technology but differ in the route of administration and dosing regimen. ${ }^{7}$

Therapy is generally initiated with 1 of the 4 self-injectable products and is determined on the basis of patient and clinician preference as well as response. These agents are considered immunomodulators and work on the inflammatory aspect of MS as well as other pathways. In general, the DMAs reduce attack rates by about $30 \%$ and decrease the accumulation of lesions (areas of demyelination of neurons in the brain and spine) detected by magnetic resonance imaging (MRI) ${ }^{3-5}$ Despite the anti-inflammatory effects of these medications, they have not been shown to completely prevent the progression to disability for patients; however, they likely slow progression. ${ }^{5,8}$

Side effects of the medications include flu-like symptoms, injection site reactions, and increases in liver enzymes, which generally disappear in the first few months of treatment. ${ }^{2}$ These side effects can make compliance a challenge for some patients. Patients may develop neutralizing antibodies to the interferon products, which potentially make the drugs less effective over time..$^{5-7}$ Neutralizing antibodies develop more frequently to interferon beta-lb than to either of the interferon beta-la products, and more frequently to SC than to IM interferon beta-la. ${ }^{7}$ The persistence of neutralizing antibodies also differs by product, with interferon beta-la associated with greater persistence than interferon beta-1b. ${ }^{9}$ A 2007 study reported that neutralizing antibodies affected relapse rates and MRI findings but not disability measures. ${ }^{9}$ Consideration of the immunogenicity of the interferon products may be warranted when initiating therapy or if therapy is failing. ${ }^{5,7}$
Because of the current recommendation for life-long pharmacotherapy, it is important to understand the pharmacotherapy cost implications. Prescott et al. found that the average annual cost for MS patients was $\$ 12,879$ in $2004,64.8 \%$ of which was attributable to the cost of prescription drugs and $61.4 \%$ for the DMAs specifically. ${ }^{10}$ For a subset of MS patients who had at least 1 pharmacy claim for a DMA in 2004 (57.5\%), the medication expenditure accounted for $75.3 \%$ of the total medical costs. ${ }^{10}$ Because of the significant medication cost associated with the treatment of MS, insurers analyze claims data to evaluate medication utilization, medication expenditure, regional variations, and member out-of-pocket (OOP) costs to better understand the management considerations associated with MS pharmacotherapy. In addition, insurers should understand the proportion of self-injectable MS spend processed through the medical and pharmacy benefit, as this information can lead to better management of these medications.

To our knowledge, limited information is available on trends in MS utilization, cost, and the proportion of expenditures attributable to pharmacy and medical benefits. To respond to this need, Prime Therapeutics, a pharmacy benefits manager with approximately 10 million members throughout the United States, analyzed its self-injectable MS pharmacy benefit utilization and expenditure data overall and by region for a 45-month period beginning in January 2004 and ending in September 2007.

\section{Market Share for Self-Injectable MS Drugs in the Third Quarter of 2007}

From pharmacy claims, the 4 self-injectable MS drugs were identified from the National Drug Code field using the Generic Product Identifier (GPI, Medi-Span). GPI beginning 624030604564 identified IM interferon beta-la; GPI beginning 624030605021 identified interferon beta-1b; GPI beginning 624000301064 or 624000301021 identified glatiramer acetate; and GPI beginning 624030604520 identified SC interferon beta-la (Table 1).

Figures 1 and 2 show the variation in market share for members with pharmacy benefits during the third quarter of 2007, measured by pharmacy claim count and actual paid ingredient cost after subtracting pharmacy network discounts. Data for the third quarter of 2007 represent approximately 9 million members. For all analyses, each mail order claim (dispensed with up to a 90-day supply) was weighted as 3 claims, and each community pharmacy claim (dispensed with up to a 34-day supply) was counted as 1 claim. Formulary medications included IM interferon beta-la, SC interferon beta-la, and glatiramer for members in all geographic regions, with the exception of $51.8 \%$ of the Central Plains members whose formulary was limited to IM interferon beta-la and glatiramer.

In all geographic regions, glatiramer and IM interferon beta-la had the largest market share, together accounting for $59.7 \%$ to 
Utilization, Cost Trends, and Member Cost-Share for Self-Injectable Multiple Sclerosis Drugs-

Pharmacy and Medical Benefit Spending From 2004 Through 2007

\begin{tabular}{|c|c|c|c|c|c|c|c|}
\hline & Generic Name & Brand Name & Route & $\begin{array}{l}\text { Frequency of } \\
\text { Injections }\end{array}$ & Manufacturer & HCPCS* & $\mathrm{GPI}^{\dagger}$ \\
\hline \multirow[t]{4}{*}{ Self-injectable } & Interferon beta-la & Avonex & IM & Once per week & Biogen Idec & $\begin{array}{l}J 1825 \\
\text { Q3025 }\end{array}$ & 624030604564 \\
\hline & Interferon beta-lb & Betaseron & SC & Every other day & Berlex Laboratories & J1830 & 624030605021 \\
\hline & Glatiramer acetate & Copaxone & SC & Daily & Teva Neuroscience & J1595 & $\begin{array}{l}624000301064 \\
624000301021\end{array}$ \\
\hline & Interferon beta-la & Rebif & SC & 3 times per week & Serono & Q3026 & 624030604520 \\
\hline \multirow[t]{2}{*}{ Infusion } & Mitoxantrone & Novantrone & IV & $\begin{array}{l}4 \text { times per year } \\
\text { (lifetime limit of } \\
8-12 \text { doses) }\end{array}$ & Serono & & \\
\hline & Natalizumab & Tysabri & IV & Monthly & $\begin{array}{l}\text { Biogen Idec and Elan } \\
\text { Pharmaceuticals }\end{array}$ & & \\
\hline \multicolumn{8}{|c|}{$\begin{array}{l}\text { * For most payers, J1825 and Q3025 are specific to IM interferon beta-1a and Q3026 is specific to SC interferon beta-1a, but claims with J1825 occasionally include } \\
\text { SC interferon beta-1a. } \\
\dagger \text { GPI begins with these } 12 \text { characters of a total 14-character GPI number. } \\
\text { GPI= Generic Product Identifier (Medi-Span); HCPCS=Healthcare Common Procedure Coding System; IM=intramuscular; IV=intravenous; MS= multiple sclerosis; } \\
\text { SC= subcutaneous. }\end{array}$} \\
\hline
\end{tabular}
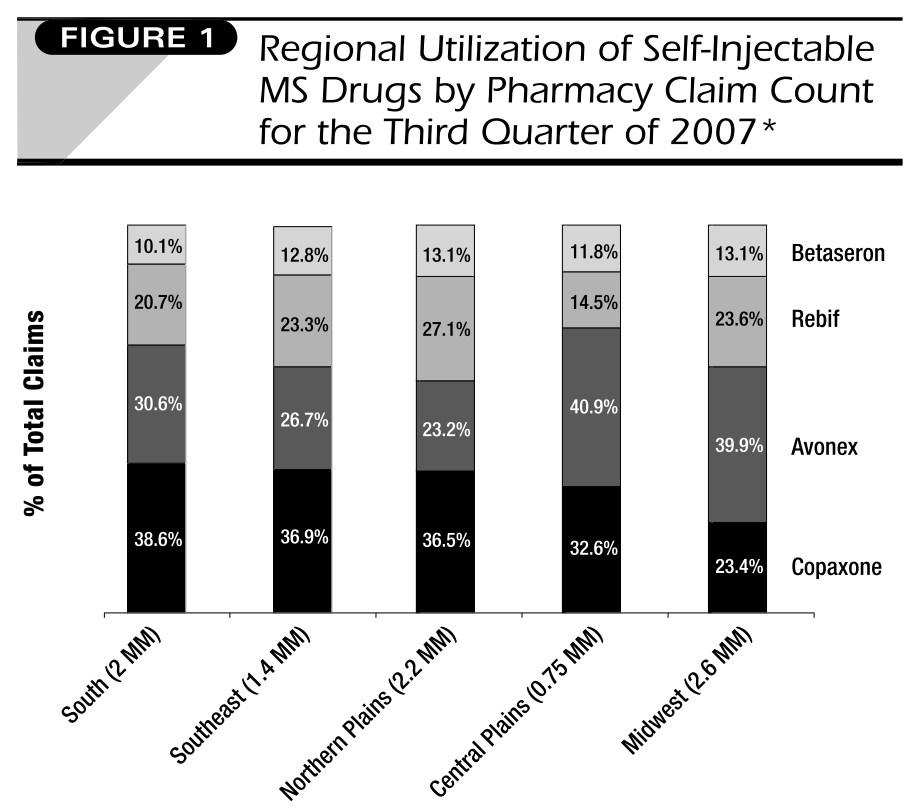

*Multiple sclerosis medications analyzed: intramuscular interferon beta-1a (pharmacy claims with GPI beginning 624030604564), interferon beta-1b (GPI beginning 624030605021), glatiramer acetate (GPI beginning 624000301064 and 624000301021), and subcutaneous interferon beta-1a (GPI beginning 624030604520). All mail order claims (dispensed with up to a 90-day supply) were counted as 3 claims, and community pharmacy claims (dispensed with up to a 34-day supply) were counted as 1 claim.

GPI=Generic Product Identifier; $M M=$ million members; $M S=$ multiple sclerosis
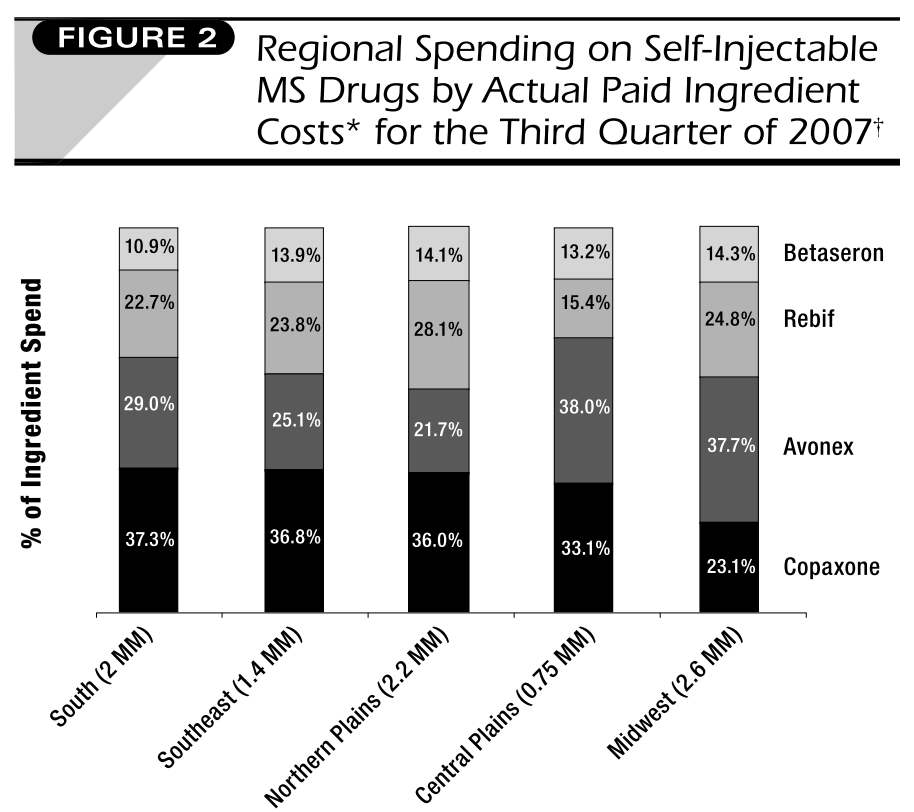

* Ingredient costs were those after pharmacy network discounts were subtracted. † Multiple sclerosis medications analyzed: intramuscular interferon beta-1a (pharmacy claims with GPI beginning 624030604564), interferon beta-1b (GPI beginning 624030605021), glatiramer acetate (GPI beginning 624000301064 and 624000301021), and subcutaneous interferon beta-1a (GPI beginning 624030604520). All mail order claims (dispensed with up to a 90-day supply) were counted as 3 claims, and community pharmacy claims (dispensed with up to a 34-day supply) were counted as 1 claim.

GPI=Generic Product Identifier; $M M=$ million members; $M S=$ multiple sclerosis . 


\begin{tabular}{|c|c|c|c|c|c|}
\hline Medication & $\begin{array}{c}\text { Average AWP } \\
\text { Price per Unit } \\
2004 \text { Q1 } \\
\end{array}$ & $\begin{array}{c}\text { Average AWP } \\
\text { Price per Unit } \\
2007 \text { Q3 } \\
\end{array}$ & $\begin{array}{c}\text { Average AWP } \\
\text { per Claim } \\
2007 \text { Q3 } \\
\end{array}$ & $\begin{array}{l}\text { 3.75-Year } \\
\text { Increase in } \\
\text { Unit Price* }\end{array}$ & $\begin{array}{c}\text { Compound } \\
\text { Annualized Inflation } \\
\text { (Based on Unit Prices) }\end{array}$ \\
\hline IM interferon beta- $1 \mathrm{a}: 30 \mathrm{mcg}$ per $0.5 \mathrm{ml}$ & $\$ 319$ & $\$ 470$ & $\$ 1,901$ & $47.2 \%$ & $11.7 \%$ \\
\hline SC interferon beta-la: 44 mcg per $0.5 \mathrm{ml}$ & $\$ 258$ & $\$ 347$ & $\$ 2,142$ & $34.7 \%$ & $8.9 \%$ \\
\hline SC interferon beta-1b: $0.3 \mathrm{mg}$ & $\$ 92$ & $\$ 143$ & $\$ 2,225$ & $54.8 \%$ & $13.3 \%$ \\
\hline SC glatiramer: $20 \mathrm{mg}$ per $\mathrm{ml}$ & $\$ 1,303$ & $\$ 1,959$ & $\$ 2,230$ & $50.4 \%$ & $12.4 \%$ \\
\hline
\end{tabular}

$73.5 \%$ of claims and $57.7 \%$ to $71.1 \%$ of costs. Interferon beta-1b has the lowest utilization in all regions, which could be due in part to its non-formulary status. The unique formulary for the $51.8 \%$ of members in the Central Plains region is a potential explanation for the SC interferon beta-la utilization of $14.5 \%$ of claims, compared with $20.7 \%$ to $27.1 \%$ in the other geographic regions. The corollary to the lower SC interferon beta-la use in the Central Plains is higher use of IM interferon beta-la. It is unclear why members in the Midwest region utilized proportionally less glatiramer (23.4\% of claims) and more IM interferon beta-la (39.9\%) compared with other regions with the same formulary, in which $36.5 \%$ to $38.6 \%$ of claims were for glatiramer and $23.2 \%$ to $30.6 \%$ of claims were for IM interferon beta-la. Other contributing factors for medication selection could include differences in dosing frequency, route of administration, formation of neutralizing antibodies, and the perceived efficacy of the products.

Findings for the analysis of paid ingredient costs were nearly identical to the utilization analysis results (Figure 2). That would be expected, as the average wholesale prices (AWPs) per pharmacy claim among the medications were similar during the third quarter of 2007 (Table 2).

\section{Utilization and Cost Trends for Self-Injectable MS Drugs}

Analysis of price inflation from the first quarter of 2004 through the third quarter of 2007 showed that prices for all the selfinjectable MS products increased substantially by amounts ranging from $34.7 \%$ to $54.8 \%$, yielding a compound annualized rate of more than $12 \%$ (Table 2). For comparison, an analysis conducted by the American Association of Retired Persons found that prices for widely used brand-name drugs increased by 6\%-7\% annually between 2004 and 2006. ${ }^{11}$ Overall inflation as measured by the Consumer Price Index during this period was approximately $3 \%$ per year.

The overall trend in medication expenditure is composed of utilization, price inflation, and medication mix (i.e., the proportion of use of higher-cost vs. lower-cost products). Inflation and mix influence price per pharmacy claim. In this therapy class, the mix effects are small and the costs per pharmacy claim for the 4 MS medications are relatively equivalent (Table 2). The compound inflation increase in unit price of $9 \%$ to $13 \%$ mirrored the $13 \%$ annualized increase in price per claim (Table 2, Figure 3 , Table 3). Therefore, the cost trend for these medications is primarily a function of price inflation and utilization.

As shown in Figure 3, which represents claims for approximately 3 million members for whom continuous data were available over the past 3 years, per capita utilization (number of claims per 100,000 members per month) has remained relatively stable since 2004. AWP ingredient cost per claim produced most of the increase in total per capita expenditure (AWP per member per month [PMPM]). As the quantity dispensed per claim decreased slightly throughout this time frame, price inflation was the major driver of the increase in expenditure. AWP was used in these analyses because contract rates with pharmacies are confidential and only brand-name products are included in this analysis. In addition, according to the U.S. Congressional Budget Office, "AWP tends to have a consistent relationship with average transaction prices for [brand] drugs." ${ }^{12}$

From the first quarter of 2004 through the third quarter of 2007, the compound annualized increases in AWP PMPM expenditure, AWP ingredient cost per claim, and number of claims per 100,000 members per month for self-injectable MS medications were $13.6 \%, 13.0 \%$, and $0.5 \%$, respectively (Table 3 and Figure 3). Over the 45-month period, the percentage of all pharmacy expenditures that were attributable to self-injectable MS medications increased from $1.8 \%$ to $2.5 \%$. In the third quarter of 2007 , absolute values for MS self-injectable AWP PMPM spend, AWP price per claim, and number of claims per 100,000 members per month were $\$ 1.74, \$ 2,119$, and 82.2 , respectively. Therefore, $\$ 1$ of every $\$ 40$ of pharmacy benefit dollars is spent on self-injectable MS medications, and volume is 82.2 claims per month per 100,000 insured members. 


\section{FIGURE 3 Pharmacy Benefit Trend for the Self-Injectable MS Drugs*}

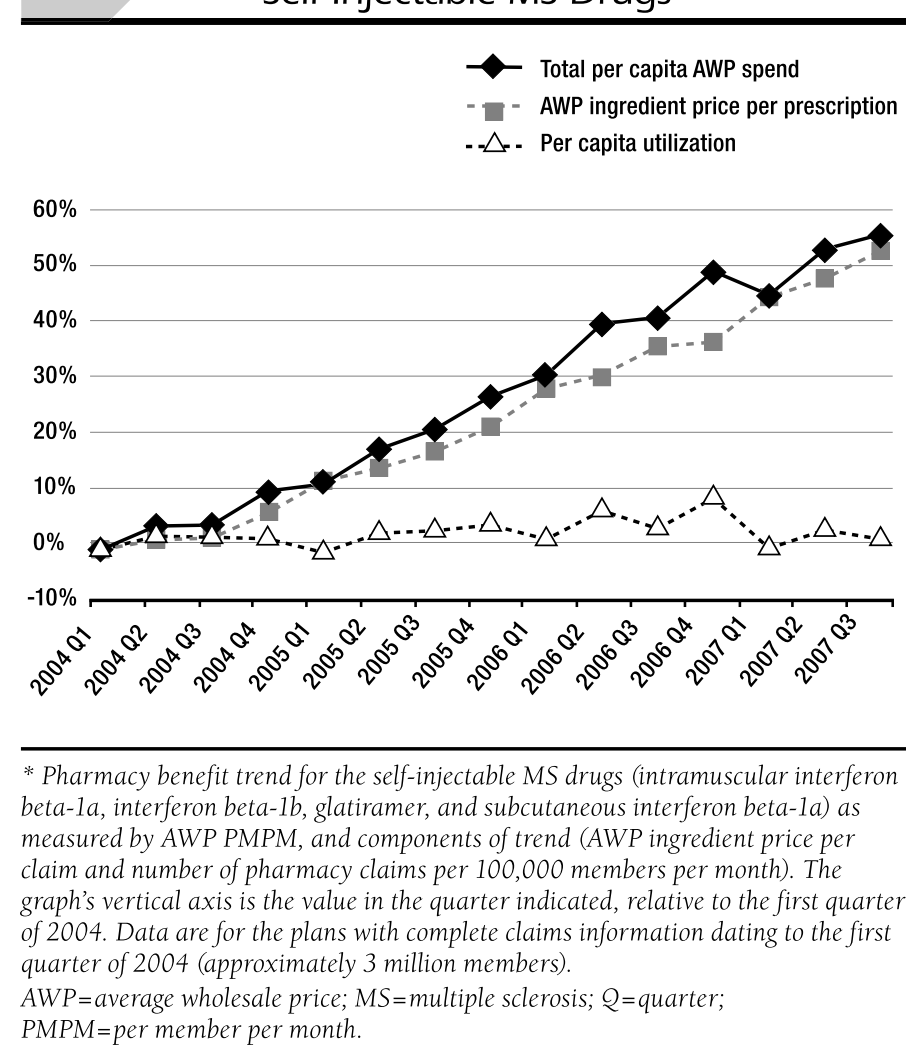

* Pharmacy benefit trend for the self-injectable MS drugs (intramuscular interferon beta-1a, interferon beta-1b, glatiramer, and subcutaneous interferon beta-1a) as measured by AWP PMPM, and components of trend (AWP ingredient price per claim and number of pharmacy claims per 100,000 members per month). The graph's vertical axis is the value in the quarter indicated, relative to the first quarter quarter of 2004 (approximately 3 million members)

AWP=average wholesale price; $M S=$ multiple sclerosis; $Q=$ quarter

\section{Member Out-Of-Pocket Cost Trends for Self-Injectable MS Drugs}

As the self-injectable MS total AWP per pharmacy claim increased substantially to $\$ 2,119$, the median OOP cost per claim paid by members increased from $\$ 20$ in the first quarter of 2004 to $\$ 30$ in the first quarter of 2007 (Figure 4). For all of 2004, the median OOP cost per claim was $\$ 15$ and members paid a mean of $\$ 52$ OOP per claim, representing 3.7\% of total MS drug cost (Table 4). The proportion of member cost-share was essentially unchanged in 2007 at 3.8\%, with a median OOP cost of $\$ 25$ per claim and a mean OOP of $\$ 79$ per claim.

Seasonal trends in OOP costs are apparent, especially when following the mean (Figure 4). The bulk of the MS member OOP costs are spent in the first quarter of the calendar year and decline throughout the year as some members reach pharmacy deductibles and OOP maximums. A portion of members pay for their entire therapies OOP or have a benefit design that requires them to pay for a percentage of the medication. This highly skewed distribution in OOP cost pushes the mean higher than the 75th percentile. For example, during the first quarter of 2007, 5\% paid $\geq \$ 517$ (95th percentile), and $10 \%$ paid $\geq \$ 355$ (90th percentile),
TABLE 3 Pharmacy Benefit Trend for the Self-Injectable MS Drugs*

\begin{tabular}{l|c|c|c|c}
\hline Quarter & $\begin{array}{c}\text { AWP } \\
\text { PMPM } \dagger\end{array}$ & $\begin{array}{c}\text { Average } \\
\text { AWP } \\
\text { per Claim }\end{array}$ & $\begin{array}{c}\text { Claims per } \\
\mathbf{1 0 0 , 0 0 0} \\
\text { Members } \\
\text { Per Month }\end{array}$ & $\begin{array}{c}\text { Proportion } \\
\text { of Total } \\
\text { Pharmacy } \\
\text { Spend }\end{array}$ \\
\hline 2004 Q1 & $\$ 1.11$ & $\$ 1,381$ & 80.7 & $1.8 \%$ \\
\hline 2004 Q2 & $\$ 1.16$ & $\$ 1,406$ & 82.6 & $1.8 \%$ \\
\hline 2004 Q3 & $\$ 1.16$ & $\$ 1,410$ & 82.5 & $1.8 \%$ \\
\hline 2004 Q4 & $\$ 1.25$ & $\$ 1,495$ & 83.6 & $1.8 \%$ \\
\hline 2005 Q2 & $\$ 1.24$ & $\$ 1,551$ & 80.3 & $1.8 \%$ \\
\hline 2005 Q3 & $\$ 1.35$ & $\$ 1,583$ & 83.1 & $1.9 \%$ \\
\hline 2006 Q1 & $\$ 1.42$ & $\$ 1,685$ & 84.3 & $1.9 \%$ \\
\hline 2006 Q2 & $\$ 1.46$ & $\$ 1,779$ & 82.2 & $2.2 \%$ \\
\hline 2006 Q3 & $\$ 1.58$ & $\$ 1,883$ & 83.7 & $2.4 \%$ \\
\hline 2006 Q4 & $\$ 1.67$ & $\$ 1,894$ & 88.1 & $2.3 \%$ \\
\hline 2007 Q2 & $\$ 1.71$ & $\$ 2,051$ & 83.5 & $2.4 \%$ \\
\hline 2007 Q3 & $\$ 1.74$ & $\$ 2,119$ & 82.2 & $2.5 \%$ \\
\hline
\end{tabular}

* Pharmacy benefit trend for the self-injectable MS drugs (intramuscular interferon beta-1a, interferon beta-1b, glatiramer, and subcutaneous interferon beta-1a) as measured by AWP PMPM, and components of trend (AWP ingredient price per claim and number of pharmacy claims per 100,000 members per month). Data are for the plans with complete claims information dating to the first quarter of 2004 (approximately 3 million members).

$\dagger$ AWP PMPM was determined for the entire quarter of analysis (i.e., total AWP for the quarter divided by total member months for the quarter).

$A W P=$ average wholesale price; $M S=$ multiple sclerosis; $P M P M=$ per member per month; $Q=$ quarter.

while $75 \%$ paid $\$ 100$ or less ( 75 th percentile) (data not shown). During the third quarter of $2007,5 \%$ paid $\geq \$ 100$ (95th percentile), and $75 \%$ paid $\$ 35$ or less (75th percentile).

\section{Trends in the Proportions of Self-Injectable} MS Drug Expenditure Processed Through the Medical Versus Pharmacy Benefit

An analysis of an integrated medical and pharmacy claims data set for 1.8 million members enrolled in a single commercial state Blue Cross Blue Shield (BCBS) health plan in the Northern Plains region evaluated the proportions of self-injectable MS medication expenditures that were processed through the medical and pharmacy benefits. These 1.8 million members had their claims paid by a single BCBS payer for both fully insured and self-insured members. Self-injectable MS drugs were identified from medical claims using Healthcare Common Procedure Coding System 


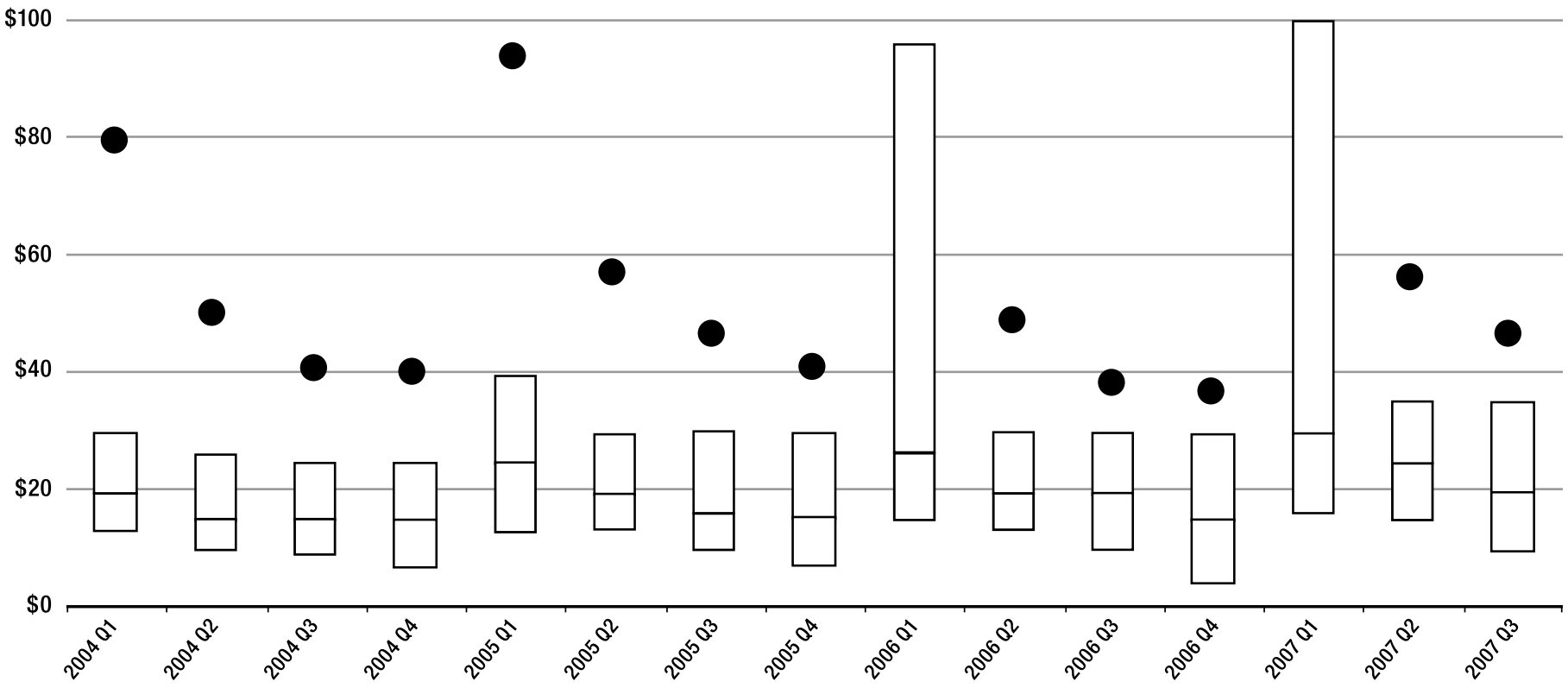

* Self-injectable MS drugs are intramuscular interferon beta-1a, interferon beta-1b, glatiramer, and subcutaneous interferon beta-1a. The boxes represent the 25 th, 50th, and 75 th percentiles (bottom of box $=25$ th percentile, middle line $=50$ th percentile, top of box $=75$ th percentile) and the dots represent the means.

MS=multiple sclerosis; $Q=q u a r t e r$.

\begin{tabular}{l} 
TABLE 4) Member Out-of-Pocket Cost for \\
Self-Injectable MS Drugs: 2004-2007 \\
\hline
\end{tabular}

codes: J1595 for glatiramer, J1830 for SC interferon beta-1b, Q3026 for SC interferon beta-1a, and Q3025 and J1825 for IM interferon beta-1a. J1825 is generally used only for IM interferon beta-1a, but SC interferon beta-la does occasionally appear billed under this code (Table 1).

As shown in Figure 5, 2.5\% of the total expenditure was processed through the medical benefit in 2004. In 2007, selfinjectable MS spend processed through the medical benefit had declined by more than 50\% from 2004 to less than 1.2\% of the total spend. For this insurer and others that process the majority of self-injectable MS medications through their pharmacy benefit manager, medication management (e.g., clinical programs, benefit design) should be focused on the pharmacy benefit instead of the medical benefit.

\section{Discussion}

Multiple sclerosis is a debilitating disease and the goal of current therapies is to decrease the patient's number of attacks in hopes 
of slowing the progression to disability. ${ }^{2-4}$ Multiple sclerosis pharmacotherapy is expensive, and now consumes $\$ 1$ of every $\$ 40$ pharmacy benefit dollars to pay for 82.2 claims per month per 100,000 insured members. Utilization of these self-injectable products has been relatively constant in the past 3 years. In our analysis of a single insurer for which we have both pharmacy and medical data trended back to 2004, the expenditure tends to fall almost entirely under the pharmacy benefit. A similar proportion of medical and pharmacy self-injectable MS drug expenditure existed for state Blues plans in the Midwest and South (data not shown). Total medication expenditure for these products over the past 3 years has increased $13.6 \%$ annually and has been almost entirely driven by price increases. Multiple sclerosis medication price inflation is 4 times the standard inflationary rate for all consumer goods and 2 times the inflation rate for commonly used branded prescription medications.

While the median OOP cost per pharmacy claim for these 4 self-injectable MS drugs has remained constant at about $1 \%$ of the total price of these drugs, when calculated as the mean OOP cost health plan members today are paying more on a per-claim basis for these products than in 2004. The newer benefit designs, such as high-deductible health plans with savings options, are likely contributing to the increase in mean member OOP expenditures. However, the mean member contribution per claim still remains less than $4 \%$ of the total AWP price paid, with the insurer absorbing the bulk of the pharmaceutical manufacturers' price increases. The wide variance between the mean and median member OOP cost per claim found in our analyses indicates that the OOP cost distribution is skewed (i.e., a small portion of members is paying high OOP cost, especially in the first quarter of each year) (Figure 4). Further analysis of the distribution in OOP cost is needed to determine the percentage of members paying high $\mathrm{OOP}$ cost and the amount being paid.

Price inflation for self-injectable MS drugs has pushed the average price per claim up 53\% in 3.5 years, from an average $\$ 1,381$ in first-quarter 2004 to $\$ 2,119$ in third-quarter 2007 (Table 3). Since utilization has remained fairly constant over this period, drug cost PMPM for these self-injectable MS drugs has risen 57\%, from \$1.11 PMPM in first-quarter 2004 to $\$ 1.74$ PMPM in third-quarter 2007, driven by price inflation. Meanwhile, median member OOP cost and average member cost-share have changed little over this 3.5-year period. It is unclear whether insurers will continue to absorb the price increases or further shift the burden to their members. Further investigation into the relationship between member OOP expenses and utilization is necessary, as is keeping a watchful eye on price inflation.
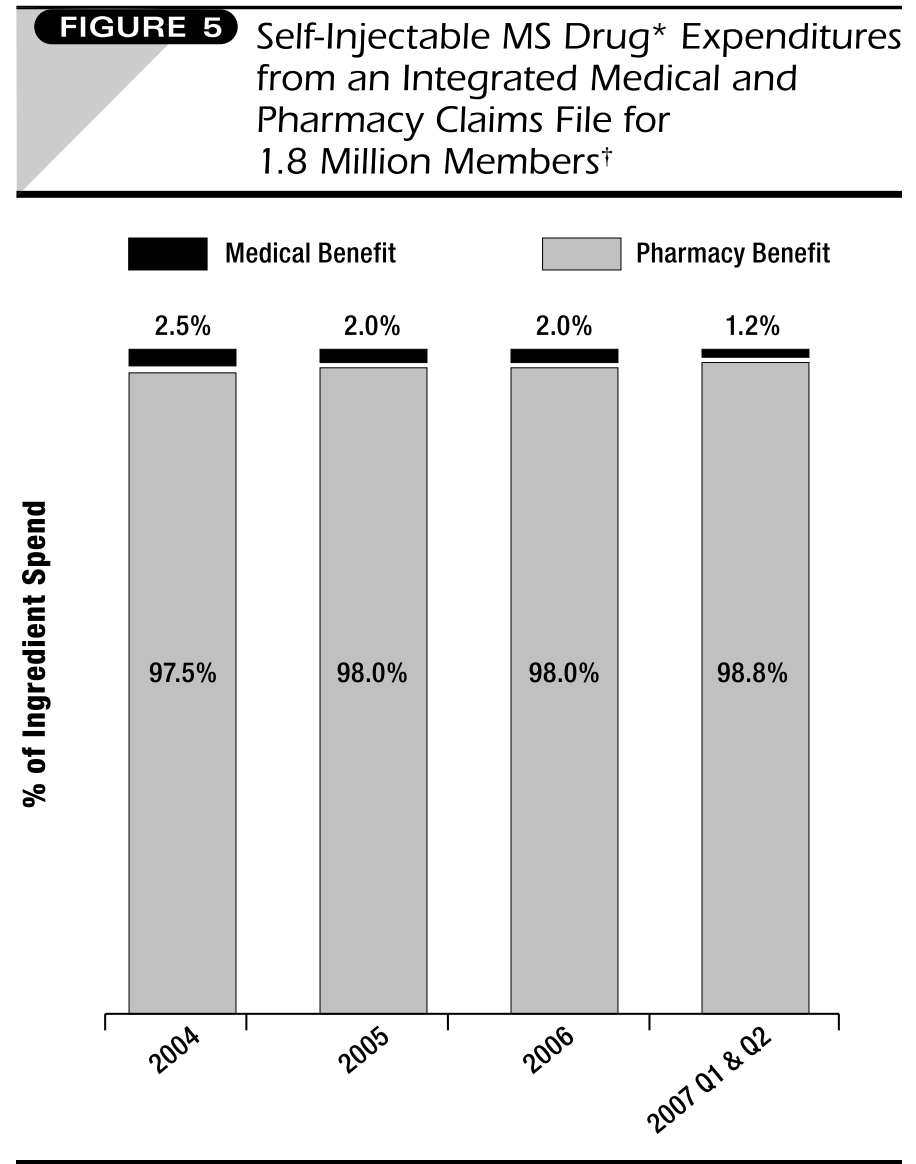

* Multiple sclerosis drug claims processed through the pharmacy benefit were intramuscular interferon beta-1a (GPI code beginning 624030604564), interferon beta-1b (GPI beginning 624030605021), glatiramer (GPI beginning 624000301064 and 624000301021) and subcutaneous interferon beta-1a (GPI beginning 624030604520). MS medications processed through the medical benefit included interferon beta-1a (HCPCS codes J1825, Q3025, and 23026), interferon beta-1b (HCPCS code J1830), and glatiramer (HCPCS code J1595).

$\dagger$ Members in a single Blue Cross Blue Shield plan located in the Northern Plains region who have integrated pharmacy and medical benefits.

GPI $=$ Generic Product Identifier; HCPCS=Healthcare Common Procedure Coding System; MS=multiple sclerosis; $Q=$ quarter.

\section{Authors}

APRIL M. KUNZE, PharmD, and BRENT W. GUNDERSON, PharmD, are senior clinical pharmacists, Prime Therapeutics, Eagan, Minnesota; PATRICK P. GLEASON, PharmD, FCCP, BCPS, is director, Outcomes Assessment, Prime Therapeutics; ALAN H. HEATON, PharmD, is pharmacy director, Blue Cross Blue Shield of Minnesota, Eagan; and STEVEN V. JOHNSON, PharmD, BCPS, is senior director, Clinical Consultative Services, Prime Therapeutics.

AUTHOR CORRESPONDENCE: April M. Kunze, PharmD, Senior Clinical Pharmacist, Prime Therapeutics, 1305 Corporate Center Drive, Eagan, MN 55121. Tel.: 651.414.4156; Fax: 651.414.4306; E-mail:akunze@primetherapeutics.com 


\section{Utilization, Cost Trends, and Member Cost-Share for Self-Injectable Multiple Sclerosis Drugs- Pharmacy and Medical Benefit Spending From 2004 Through 2007}

\section{DISCLOSURES}

April M. Kunze, Brent W. Gunderson, Patrick P. Gleason, and Steven V. Johnson are employees of Prime Therapeutics, a pharmacy benefits management company that provides services nationwide. Its client base includes Blue Cross and Blue Shield plans, employer and union groups, and thirdparty administrators. Headquartered in St. Paul, MN, Prime Therapeutics is collectively owned by 10 Blue Cross and Blue Shield plans, subsidiaries, or affiliates of those plans. Alan $\mathrm{H}$. Heaton is an employee of Blue Cross Blue Shield of Minnesota, a health insurance company.

Kunze was the principal author of this article. Study concept and design was primarily the work of Kunze, with input from the coauthors. Data collection was the work of Gunderson and Gleason; data interpretation and manuscript revision were the work of all the authors. Heaton was involved in the medical/pharmacy integration analysis. The authors report no financial or other conflicts of interest related to the subject of this article.

\section{REFERENCES}

1. National Multiple Sclerosis Society. What is multiple sclerosis? August 17, 2007. Available at: www.nationalmssociety.org/site/ PageServer?pagename=HOM_LIB_brochures_what_is_ms. Accessed August 21, 2007

2. Rizvi SA, Agius MA. Current approved options for treating patients with multiple sclerosis. Neurology. 2004;63(12):S8-S14.

3. Miller J. The importance of early diagnosis of multiple sclerosis. J Manag Care Pharm. 2004;10(3):S4-S9. Available at: www.amcp.org/data/jmcp/ June04Supplement1.pdf. Accessed October 11, 2007.

4. National Multiple Sclerosis Society. The disease-modifying drugs. November 2006. Available at: www.nationalmssociety.org/docs/HOM/ brochures/DiseaseModifyingDrugs.pdf. Accessed August 21, 2007.

5. National Multiple Sclerosis Society. Expert opinion paper. Changing therapy in relapsing multiple sclerosis: considerations and recommendations of a task force of the National Multiple Sclerosis Society. 2004. Available at: www.nationalmssociety.org/docs/HOM/Exp_ChangTherapy.pdf. Accessed August 21, 2007.

6. Goodin DS, Frohman EM, Garmany GP, et al. Disease modifying therapies in multiple sclerosis: report of the Therapeutics and Technology Assessment Subcommittee of the American Academy of Neurology and the MS Council for Clinical Practice Guidelines. Neurology. 2002;58:169-78.
7. Rossman H. Neutralizing antibodies to multiple sclerosis treatments. J Manag Care Pharm. 2004;10(3):S12-S17. Available at: www.amcp.org/ data/jmcp/June04Supplementl.pdf. Accessed October 11, 2007.

8. De Jager P, Hafler D. New therapeutic approaches for multiple sclerosis. Annual Review of Medicine. 2007;58:417-32.

9. Noronha A. Neutralizing antibodies to interferon. Neurology. 2007; 68(S4):S16-S22.

10. Prescott J, Factor S, Pill M, Levi G. Descriptive analysis of the direct medical costs of multiple sclerosis in 2004 using administrative claims in a large nationwide database. J Manag Care Pharm. 2007;13(1):44-52. Available at: www.amcp.org/data/jmcp/44-52.pdf. Accessed on October 17, 2007.

11. AARP. Trends in manufacturer prices of brand-name prescription drugs used by older Americans-2006 year-end update. Available at: http://assets. aarp.org/rgcenter/health/dd154_drugprices.pdf. Accessed October 16, 2007.

12. U.S. Congressional Budget Office. Prescription drug pricing in the private sector. January 2007. Available at: www.cbo.gov/ftpdocs/77xx/ doc7715/01-03-PrescriptionDrug.pdf. Accessed October 16, 2007.

13. Biogen Idec, Inc. Avonex (interferon beta-la) prescribing information. November 2006. Available at: www.avonex.com/msavProject/avonex.portal/ _baseurl/threeColLayout/SCSRepository/en_US/avonex/includes/footer/ prescribe_info_med_guide.xml. Accessed October 22, 2007.

14. Berlix Laboratories and Bayer Healthcare Pharmaceuticals. Betaseron (interferon beta-1b) prescribing information. September 2007. Available at: http://berlex.bayerhealthcare.com/html/products/pi/Betaseron_PI.pdf. Accessed October 22, 2007.

15. Teva Neuroscience. Copaxone (glatiramer acetate) prescribing information. May 2007. Available at: www.copaxone.com/pdf/ PrescribingInformation.pdf. Accessed October 22, 2007.

16. Serono, Inc. and Pfizer. Rebif (interferon beta-la) prescribing information. September 2005. Available at: www.mslifelines.com/_assets/ pdf/Rebif_PI.pdf. Accessed October 22, 2007.

17. Serono, Inc. Novantrone (mitoxantrone) prescribing information. September 2006. Available at: www.novantrone.com/assets/pdf/ novantrone_prescribing_info.pdf. Accessed October 22, 2007.

18. Biogen Idec and Elan Pharmaceuticals. Tysabri (natalizumab) prescribing information. June 2007. Available at: www.tysabri.com/ tysbProject/tysb.portal/_baseurl/twoColLayout/SCSRepository/en_US/tysb/ home/product-information/index.html. Accessed October 22, 2007. 